\title{
Immunoregulatory Function of Lymphatic Endothelial Cells in Tumor-draining Lymph Nodes of Human Gastric Cancer
}

\author{
MAO TOKUMOTO, HIROAKI TANAKA, YUKIE TAUCHI, TATSURO TAMURA, \\ TAKAHIRO TOYOKAWA, KENJIRO KIMURA, KAZUYA MUGURUMA, \\ MASAKAZU YASHIRO, KIYOSHI MAEDA, KOSEI HIRAKAWA and MASAICHI OHIRA \\ Department of Surgical Oncology, Osaka City University Graduate School of Medicine, Osaka, Japan
}

\begin{abstract}
Background/Aim: Lymph node metastasis is the most important prognostic factor for patients with gastric cancer. Increasing evidence suggests that lymphatic endothelial cells (LECs) regulate immune responses. The aim of this study was to examine the effect of LECs on the activation of $C D 4^{+} T$ cells. Materials and Methods: We examined the impact of cancer cells on the phenotype and production of cytokines of LECs derived from tumor-draining lymph nodes. Results: We showed that LECs inhibited $\mathrm{CD}^{+} \mathrm{T}$ cell production of cytokines, such as $I L-2, I L-10$, and INF- $\gamma$. The mRNA expression of programmed death-ligand 1 (PD-L1) and indoleamine 2, 3-dioxygenase (IDO) by LECs were significantly up-regulated when the LECS and $\mathrm{CD}^{+} \mathrm{T}$ cells were co-cultured with cells of the gastric cancer cell line, OCUM12. Conclusion: Intranodal LECs may be a key player in the induction of immune tolerance against cancer and in facilitating metastasis through lymphatic vessels in gastric cancer.
\end{abstract}

The lymphatic system has important roles, including the maintenance of tissue homeostasis by regulating tissue fluid and protein balance, and the generation of immune responses by trafficking immune cells and antigens $(1,2)$. Lymph nodes are essential immune sites that recognize foreign antigens and determine the fate of $\mathrm{T}$ cells. Lymph node stromal cells (LNSCs), which include blood endothelial cells (BECs) and lymphatic endothelial cells (LECs) as well as fibroblastic reticular cells (FRCs), were originally considered to function as structural components. Evidence has recently accumulated that LNSCs express Peripheral tissue antigens (PTAs), and that LNSCs are involved in cluster of differentiation (CD) $8^{+}$

Correspondence to: Hiroaki Tanaka, 1-4-3 Asahi-machi, Abeno-ku, Osaka 545-8585, Japan. Tel: +81 666453838, Fax: +81 666466450, e-mail: hiroakitan@med.osaka-cu.ac.jp

Key Words: Lymphatic endothelial cells, lymph nodes, tumor microenvironment, metastasis, gastric cancer.
T cell tolerance (3-5). Of LNSCs, LECs can directly suppress dendritic cell (DC) maturation and peripheral tissue antigens for auto-reactive $\mathrm{T}$ cell deletion (6). Other reports have shown that LECs interact with $\mathrm{CD} 8^{+} \mathrm{T}$ cells, cross-present tumor antigens, and directly suppress cytotoxic $\mathrm{T}$ cells by inducing apoptosis $(7,8)$.

Gastric cancer frequently displays lymph node metastasis. It is well known that lymph node metastasis is an independent prognostic factor for patients with gastric cancer. Generally, cancer cells develop an immunosuppressive microenvironment and spread from the primary site and regional lymph nodes to draining lymph nodes via immune escape $(9,10)$. However, the cellular mechanism by which an immunosuppressive environment is formed is not clear. We have previously shown the association of tumor-infiltrating immune cells with lymph node metastasis of gastric cancer $(11,12)$. With regard to LECs, we showed that intranodal lymphangiogenesis is augmented in lymph node metastasis $(13,14)$. Based on these results, we hypothesized that LECs might have a key role in developing an immunoregulatory microenvironment in the tumor-draining lymph node of gastric cancer.

In this study, we investigated the effect of interaction of $\mathrm{CD}^{+}$ $\mathrm{T}$ cells with intranodal LECs directly isolated from tumordraining lymph nodes to clarify the immunoregulatory condition in the tumor-influenced lymph node microenvironment.

\section{Materials and Methods}

LEC isolation and culture. Human lymph node specimens were obtained from patients with gastric cancer who underwent surgical treatment in Osaka City University Hospital. Lymph nodes were minced, digested with collagenase $(100 \mathrm{U} / \mathrm{ml}$; Life Technologies, Palo Alto, CA), and passed through a $70-\mu$ m nylon mesh (Corning Incorporated, Corning, NY). The cells were then seeded on collagen-coated dishes (Corning Incorporated, Corning, NY) and cultured in EBM2 (Lonza, Basal, Switzerland). Non-adherent cells were removed $72 \mathrm{~h}$ later and adherent cells were cultured until 80$90 \%$ confluent. These primary cell cultures were trypsinized and incubated with anti-human cluster differentiation (CD) 31 antibody-coated magnetic micro beads (Miltenyi Biotec, Bergish 
Gladbach, Germany). The purified $\mathrm{CD} 31^{+}$cells were cultured on collagen-coated dishes in EBM2 until 80-90\% confluent. The cells were then trypsinized and incubated with mouse anti-human podoplanin antibody $(4 \mu \mathrm{g} / \mathrm{ml}$; Relia Tech, Wolfenbüttel, Germany), which is an antibody against a lymphatic specific marker, for $45 \mathrm{~min}$ on ice. The cells were washed, resuspended, and incubated with anti-mouse IgG1-coated micro beads (Miltenyi Biotec). These CD31+ Podoplanin ${ }^{+}$cells (LECs) were further cultured. The cultured LECs were treated with INF- $\gamma$ (Miltenyi Biotec; $1 \mathrm{ng} / \mathrm{ml}$ ) for $72 \mathrm{~h}$ and were then used for further investigation.

Flow cytometry. To confirm that the purified cells were LECs, primary cell cultures were trypsinized, resuspended, and incubated with an Alexa Fluor 647-labeled mouse anti-human CD31 antibody (BD Biosciences, San Jose, CA) and an Alexa Fluor 488-labeled anti-human Podoplanin antibody (BioLegend, San Diego, CA) for $30 \mathrm{~min}$ on ice. Cultured LECs were trypsinized, resuspended, and stained with FITC-labeled mouse anti-human CD80 and HLA-DR antibodies (BD Biosciences, San Jose, CA), APC-labeled mouse anti-human CD86 and HLA-A,B,C antibodies (BD Biosciences), APC-labeled mouse anti-human CD58 (eBioscience, San Diego, $\mathrm{CA}$ ), and PE-labeled mouse anti-human PD-L1 antibodies (eBioscience, San Diego, CA) for $30 \mathrm{~min}$ on ice. Flow cytometry was then performed for all cells using the LSRII (BD Biosciences, San Jose, CA). The data were analyzed using FACS DIVA (BD Biosciences, San Jose, CA).

$T$ cell isolation and culture. The cells were resuspended in PBS supplemented with $1 \%$ fetal bovine serum (FBS; Nichirei Bioscience, Tokyo, Japan) and $\mathrm{CD} 4{ }^{+} \mathrm{T}$ cells were then isolated by negative selection using a $\mathrm{CD} 4+\mathrm{T}$-cell isolation kit (Miltenyi Biotec, Tokyo, Japan). Isolated CD4 ${ }^{+} \mathrm{T}$ cells were activated using a $\mathrm{T}$ cell activation and expansion kit (Miltenyi Biotec, Tokyo, Japan), and were cultured in TexMACS medium (Miltenyi Biotec, Tokyo, Japan) with human IL-2 (Miltenyi Biotec; $10 \mathrm{IU} / \mathrm{ml}$ ).

Allogeneic LEC-T cell direct co-culture assay. To investigate CD4+ $\mathrm{T}$ cell interaction with LECs, we performed a co-culture assay. LECs were adjusted to a cell concentration of $6 \times 10^{4} / \mathrm{ml}$ and were seeded onto a collagen coated $24-w e l l$ plate. Three days later, $500 \mu \mathrm{l}$ of $\mathrm{CD}^{+}{ }^{+} \mathrm{T}$ cells, adjusted to a cell concentration of $6 \times 10^{5} / \mathrm{ml}$ in TexMACS medium, were added (1:10 ratio). After co-culture for three days, RNA was extracted from the LEC and T cells

Tumor-LEC-T cell co-culture system. The OCUM12 cell line was previously established from scirrhous gastric cancer in Osaka City University (15). OCUM12 cells were maintained in DMEM (Wako Pure Chemical Industries, Ltd., Osaka, Japan) supplemented with $10 \%$ FBS and $20 \%$ penicillin-streptomycin (Wako Pure Chemical Industries, Ltd., Osaka, Japan). OCUM12 cells were adjusted to a cell concentration of $2 \times 10^{4} / \mathrm{ml}$ and $200 \mu \mathrm{l}$ of these cells were plated onto Millicell ${ }^{\circledR}$ cell culture inserts $(3 \mu \mathrm{m}$ pore, $12 \mathrm{~mm}$ Diameter; Merck, Darmstadt, Germany). The cells were incubated for $24 \mathrm{~h}$ at $37^{\circ} \mathrm{C}$ under $5 \% \mathrm{CO}_{2}$ to allow the tumor cells to attach to the filters. The filters were then transferred to a collagen coated 24-well plate on which LEC and T cells were seeded, and were incubated at $37^{\circ} \mathrm{C}$ under $5 \% \mathrm{CO}_{2}$ for 3 days in $500 \mu \mathrm{l}$ of fresh TexMACS medium. After co-culture for 3 days, RNA was extracted from the LEC and $\mathrm{T}$ cells.
$R N A$ extraction and reverse transcription $(R T)$ reaction. Total RNA was extracted using the RNeasy ${ }^{\circledR}$ mini kit (QIAGEN, Tokyo, Japan) according to the protocol provided by the manufacturer. Total RNA was reverse transcribed for the synthesis of single stranded cDNA using the ReverTra Ace ${ }^{\circledR} \mathrm{qPCR}$ RT Master Mix (TOYOBO, Osaka, Japan) according to the manufacturer's instructions. The RT reaction was performed at $37^{\circ} \mathrm{C}$ for $15 \mathrm{~min}$, $50^{\circ} \mathrm{C}$ for $5 \mathrm{~min}$, and $98^{\circ} \mathrm{C}$ for $5 \mathrm{~min}$.

Quantitative reverse transcription-polymerase chain reaction $(q R T-P C R)$. The mRNA expression of interleukin 2 (IL-2), interleukin 10 (IL-10), interleukin 12 (IL-12), and indoleamine 2, 3 -dioxygenase (IDO) in LEC, and of IL-2, IL-10, and INF- $\gamma$ in CD4 T cells was detected using qRT-PCR. Assays were performed using TaqMan ${ }^{\circledR}$ PCR core reagents and the reactions were recorded and analyzed using the ABI PRISM ${ }^{\circledR} 7000$ Sequence Detection System (Thermo Fisher Scientific Inc., Tokyo, Japan). After an initial denaturation for $10 \mathrm{~min}$ at $95^{\circ} \mathrm{C}$, the samples were subjected to 40 cycles of PCR $\left(95^{\circ} \mathrm{C}\right.$ for $15 \mathrm{sec}$ and $60^{\circ} \mathrm{C}$ for 1 min, per cycle). To analyze the ratio of gene transcription levels, glyceraldehyde 3-phosphate dehydrogenase (GAPDH) was used as an internal control. Relative target gene expression was determined using the $2^{-\Delta \Delta \mathrm{Ct}}$ method. All experiments were performed at least in triplicate, and the mean values were adopted for further calculation.

Statistical analysis. Mean values between two groups were compared using Student's $t$-test. All $p$-values were given for twosided testing. $p$-Values $<0.05$ were considered to be statistically significant. Each statistical analysis was performed using SPSSII (IBM Corporation, Armonk, NY) software.

\section{Results}

Intranodal LECs express MHC class II molecules and CD58 following INF-gamma stimulation. Unlike HLA-A, $\mathrm{B}, \mathrm{C}$ (MHC class I) molecules that are widely expressed in almost all nucleated cells, the expression of HLA-DR (MHC class II) molecules is limited to antigen-presenting cells (APCs) such as macrophages and dendritic cells (DCs) under steady-state conditions. However, some endothelial cells including LECs, BECs and FRCs can also up-regulate MHC-II expression during inflammation (1618). We first characterized steady-state MHC-I and MHCII expression by LECs using FACS analysis. As previously reported (19), LECs showed very low basal expression of HLA-DR and high expression of MHC-I in the steady-state (Figure 1, Table I). Upon stimulation with IFN-gamma, the surface expression of HLA-DR was highly up-regulated (Figure 1, Table I). CD58 (LFA-3), which is expressed on endothelial cells, is another co-stimulatory molecule for induction of $\mathrm{T}$ cell proliferation and cytokine production via interaction with CD2 on the surface of T cells $(17,20$, 21). FACS analysis indicated that CD58 was constitutively expressed on the surface of LECs and that its expression was enhanced following INF-gamma stimulation (Figure 2A, Table II). 


\section{Control}
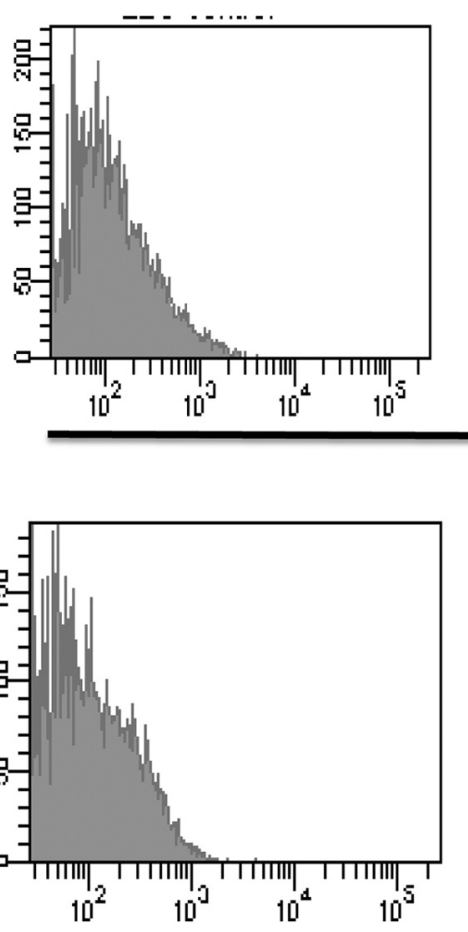

Unstimulated

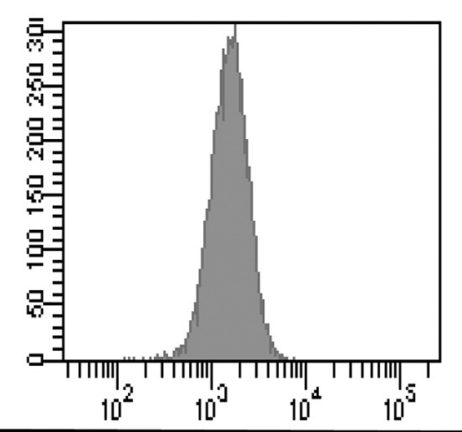

HLA-A, B, C

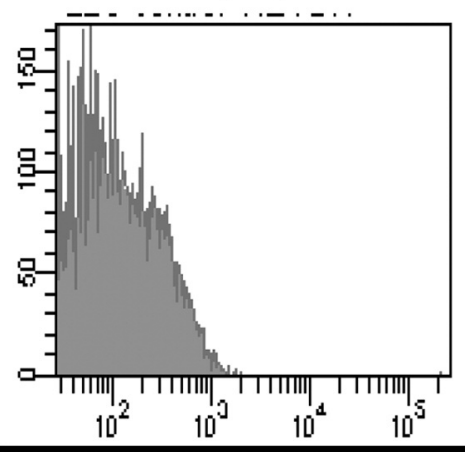



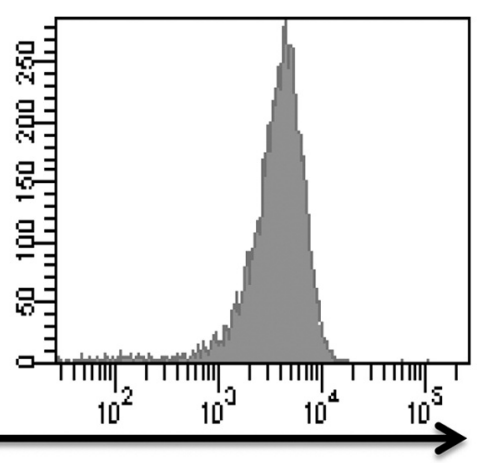

\section{HLA-DR}

Figure 1. The expression of HLA molecules on lymphatic endothelial cells (LECS). FACS analysis of the surface expression of HLA-A, B, C, and HLA-DR molecules in LECs under control, non-stimulated and INF-gamma stimulated $(1 \mathrm{ng} / \mathrm{ml}$ for $72 \mathrm{~h}$ ) conditions. LECs in the steady state expressed HLA-A, B, and C, but not HLA-DR molecules. LECs stimulated with INF-gamma up-regulated the expression of HLA molecules.

Table I. Mean fluorescence intensity of HLA molecules.

\begin{tabular}{lc}
\hline HLA-A, B, C & HLA-DR \\
\hline 390 & 189 \\
2166 & 201 \\
2612 & 1947 \\
\hline
\end{tabular}

INF-gamma stimulated LECs impaired activation of $\mathrm{CD}^{+} \mathrm{T}$ cells. To investigate the potential of LECs to induce activation of $\mathrm{CD}^{+} \mathrm{T}$ cells, we next analyzed surface expression of other co-stimulatory molecules on LECs in both the steady state and under the interferon-gamma stimulated condition. CD80 and CD86, which are well established costimulatory molecules, were not detected on the LECs under any condition (Figure 2, Table II). Consistent with a previous report (22), LECs moderately expressed the inhibitory molecule, Programmed death-ligand 1 (PD-L1) in the steady-
Table II. Mean fluorescence intensity of costimulatory molecules.

\begin{tabular}{lcccc}
\hline Treatment & CD80 & CD86 & CD58 & PD-L1 \\
\hline Control & 155 & 210 & 148 & 156 \\
None & 172 & 222 & 2992 & 406 \\
INF- $\gamma$ & 202 & 205 & 4384 & 2112 \\
\hline
\end{tabular}

state, and up-regulated both surface PD-L1 protein expression and cell PD-L1 mRNA expression upon stimulation with INF-gamma (Figure 2A and B, Table II). We further examined the effect of IFN-gamma stimulation on the mRNA expression of indoleamine 2,3-dioxygenase (IDO), an immunosuppressive enzyme, by LECs (Figure 2B). The mRNA expression of IDO in LECs was markedly increased by INF-gamma stimulation (Figure 2B). These data indicated that activated LECs regulate the immune response through inhibitory signals. The combined data suggest that LECs 
A

Control Unstimulated INF-g

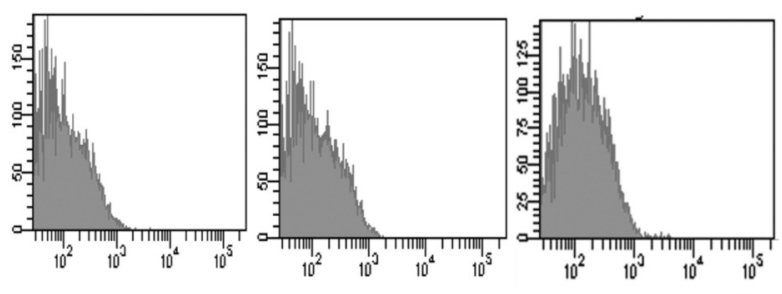

CD80

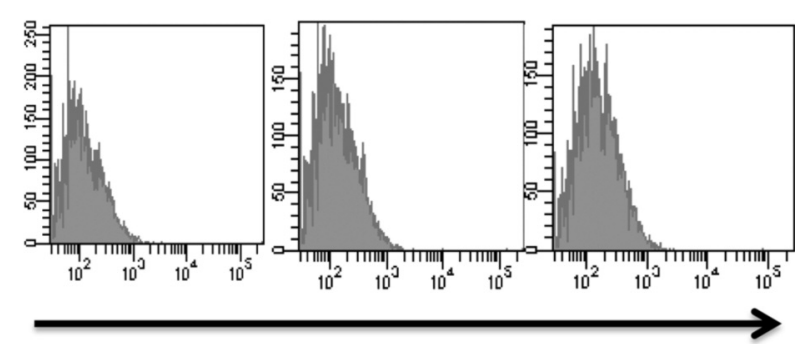

CD86

B

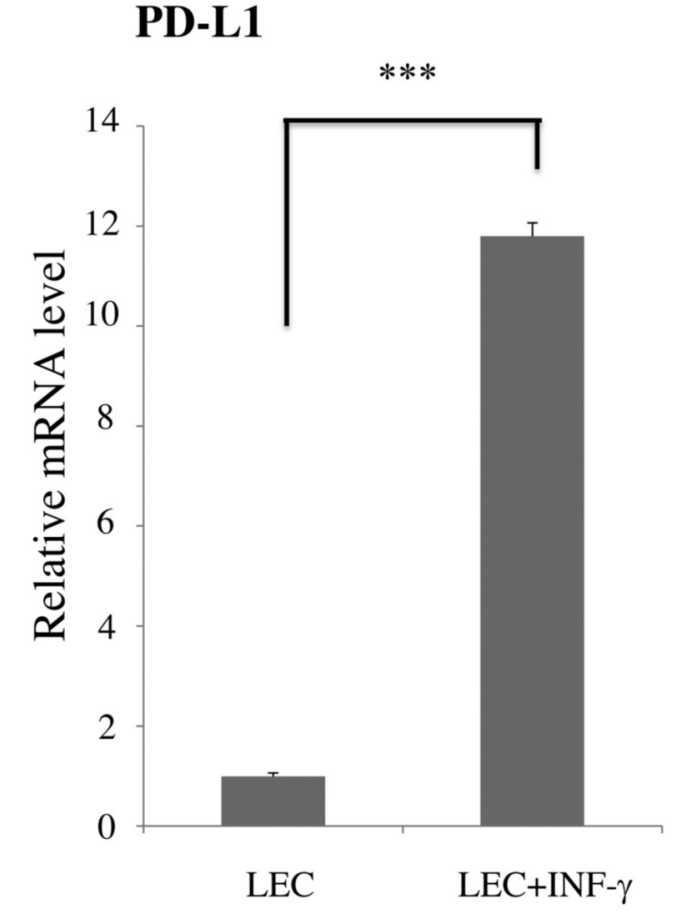

Control Unstimulated INF-g



CD58

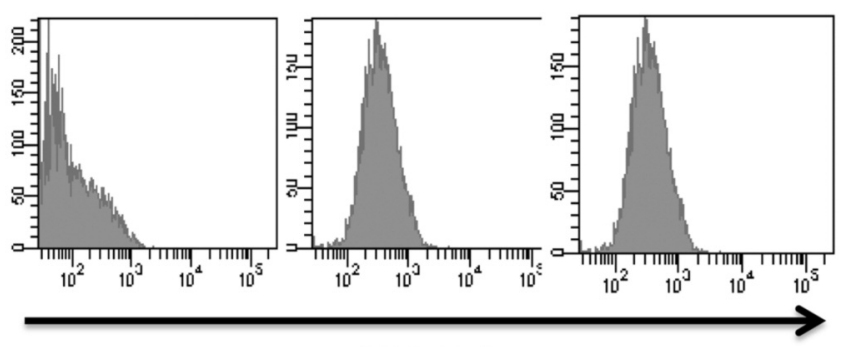

PD-L1

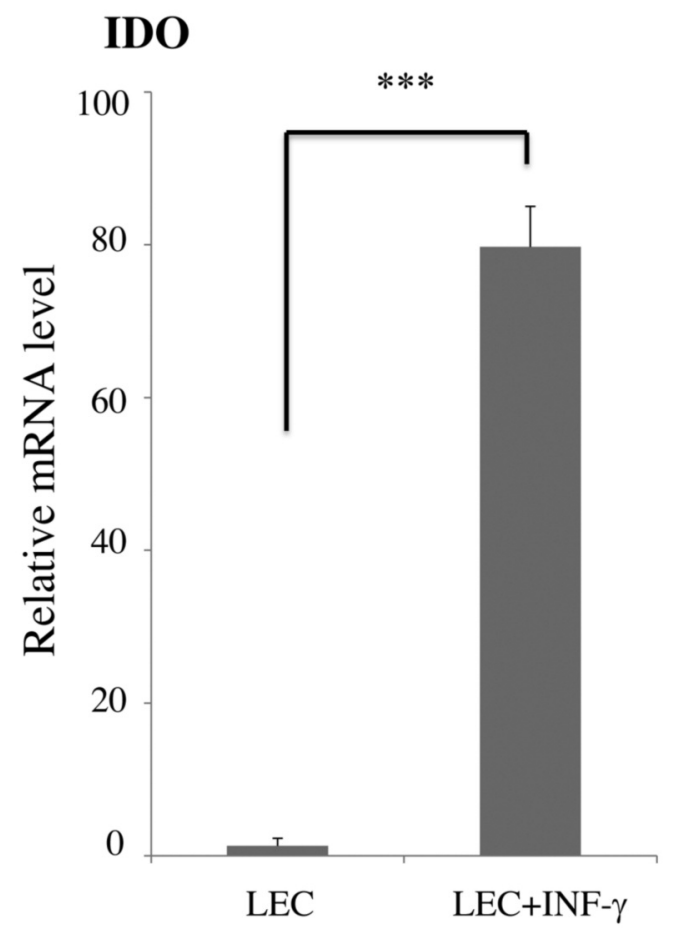

Figure 2. The expression of co-stimulatory and inhibitory molecules on LECs. A. FACS analysis of the surface expression of the co-stimulatory molecules CD58, CD80, CD86, and the inhibitory molecule, PD-L1, on LECs under control, non-stimulated, and INF-gamma stimulated (1 ng/ml for 72 h) conditions. The co-stimulatory molecules CD80 and CD86 were not expressed on LECs under any conditions. Another co-stimulatory molecule, CD58, was constitutively expressed on LECs. CD58 expression was increased when LECs were stimulated with INF-gamma. LECs also expressed the inhibitory molecule, PD-L1, and INF-gamma stimulation enhanced PD-L1 surface expression on LECs. B. qPCR analysis of the mRNA expression of inhibitory molecules by LECs. The mRNA expression of PD-L1 and IDO by LECs was significantly up-regulated under an INF-gamma-stimulated state. The mRNA expression of PD-L1 and IDO by LECs in the presence of INF-gamma (1 ng/ml for $72 \mathrm{~h}$ ) stimulation is shown relative to that in the absence of stimulation. The data represent means of quintuplets \pm standard deviation (SD). $* * * p<0.001$. 

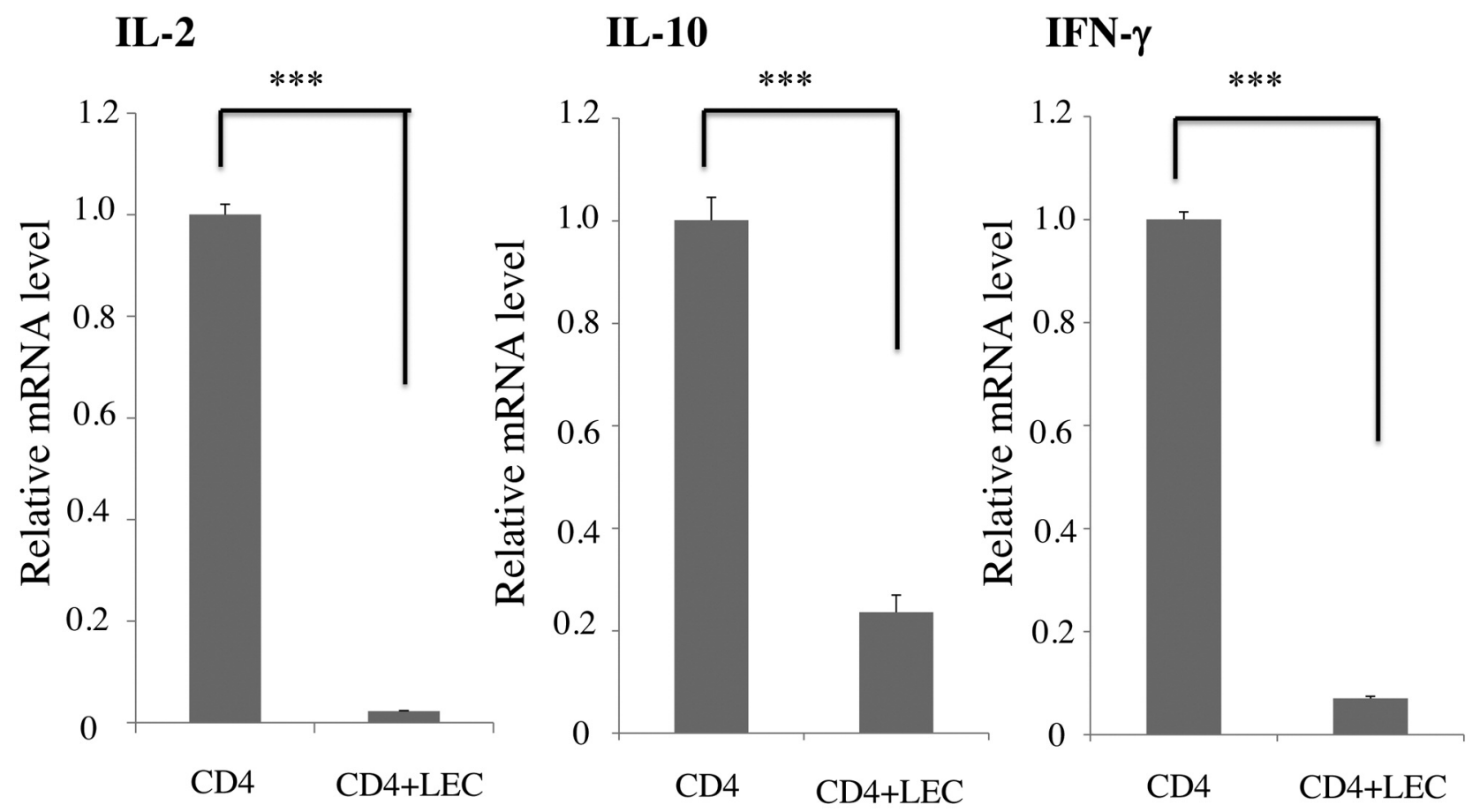

Figure 3. LECs stimulated with INF-gamma failed to activate $C D 4^{+} T$ cells. $C D 4^{+} T$ cells were co-cultured with LECs and the mRNA expression of cytokines that activate immune responses was analyzed using $q R T-P C R$. The $m R N A$ expression levels are shown relative to those of CD4 ${ }^{+} T$ cell monoculture. The data represent means of quintuplets $\pm S D . * * * p<0.001$.

regulate the immune response by interacting with $\mathrm{CD} 4^{+} \mathrm{T}$ cells via CD58 and providing co-inhibitory signals to $\mathrm{CD}^{+}$ $\mathrm{T}$ cells via PD-L1 under inflammatory conditions.

To examine the effect of IFN-gamma-stimulated LECs on the cytokine production of $\mathrm{CD}^{+}{ }^{+} \mathrm{T}$ cells, the gene expression of $\mathrm{CD}^{+}{ }^{+} \mathrm{T}$ cells co-cultured with LECs was analyzed using qRT-PCR. The mRNA levels of cytokines that promote immune responses, including IL-2, IL-10, and INF-gamma, were significantly reduced by co-culture of $\mathrm{CD}^{+} \mathrm{T}$ cells with LECs (Figure 3). This result indicated that, although $\mathrm{T}$ cells and LECs interacted with each other, the T cells failed to produce activation related cytokines.

LECs mediate immunosuppression in a tumor microenvironment. Inflammation is a key component of the tumor microenvironment. We, therefore, examined the impact of the presence of cancer cells on IFN-gamma treated LECs using a co-culture system. LECs that were co-cultured with cells of the gastric cancer cell line, OCUM12, showed lower levels of MHC class II expression compared to controls, as assessed by FACS analysis (Figure 4). Addition of OCUM12 cells into the co-culture of LECs with $\mathrm{CD} 4^{+} \mathrm{T}$ cells resulted in a significant up-regulation of the mRNA expression of PD-L1 and IDO by LECs (Figure 5). Furthermore, $\mathrm{CD}^{+}{ }^{+} \mathrm{T}$ cells co-cultured with LECs and OCUM12 cells showed higher expression of
Programmed death 1 (PD-1) than controls (Figure 5). These results suggested that cancer cells might augment the immune suppressive condition induced by LECs.

\section{Discussion}

In this study, we observed that the immune response of $\mathrm{CD} 4^{+} \mathrm{T}$ cells in the draining lymph nodes was significantly suppressed via interaction with LECs under aninflammatory condition induced by cancer cells. First, we showed that IFN-gamma stimulation enhanced the expression of MHC II and CD58 by LECs. Second, we showed that expression of the co-stimulatory molecules, CD80 and CD86, could not be detected on the surface of LECs, even following treatment with IFN-gamma. Third, we showed that cytokine production by $\mathrm{CD} 4^{+} \mathrm{T}$ cells was significantly reduced when these cells were co-cultured with LECs under an inflammatory condition. Finally, we showed that co-incubation with cancer cells led to up-regulation of the expression of several immune regulatory molecules by LECs and CD4 ${ }^{+} \mathrm{T}$ cells.

Lymph node metastasis is one of the most important prognostic factors in gastric cancer. Generally, the main function of the secondary lymphoid organs, including lymph nodes, is to initiate adaptive immune responses. Lymph nodes are important sites for the maintenance not only of 


\section{$\mathrm{LEC}+\mathrm{IFN}-\gamma$}



LEC+IFN-g+OCUM12

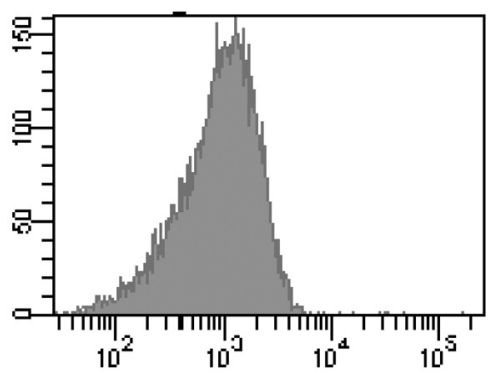

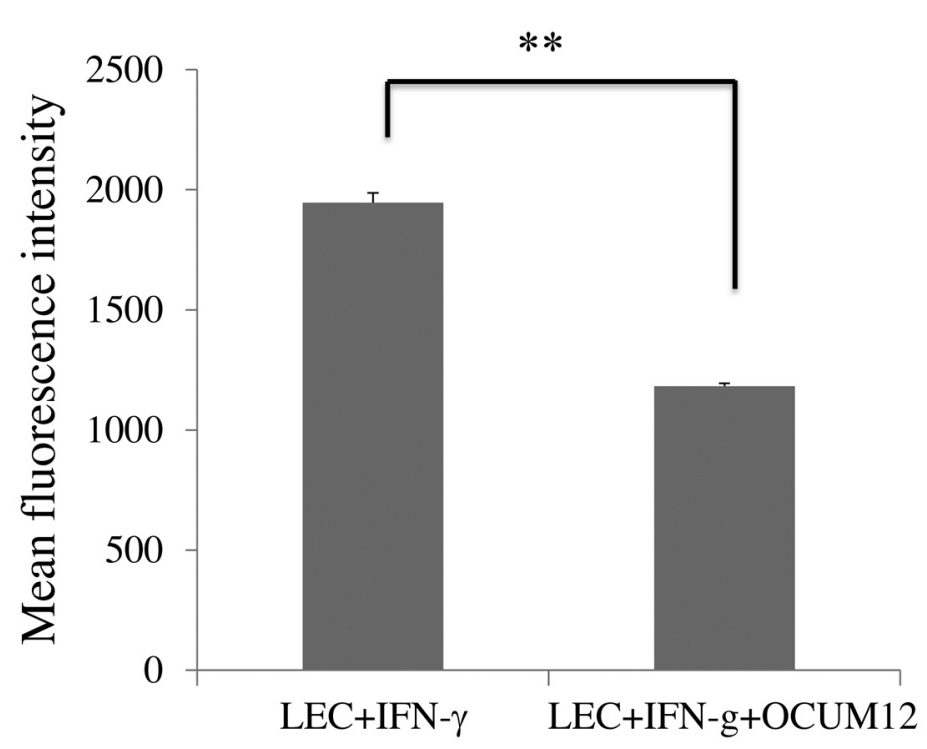

Figure 4. The expression of MHC class II molecules by LECs co-cultured with IFN-gamma in the presence or absence of cancer cells. LECs were co-cultured with cells of the OCUM12 gastric cancer cell line in the presence or absence of IFN-gamma $(1 \mathrm{ng} / \mathrm{ml}$ for $72 \mathrm{~h})$, following which the expression of MHC class II molecules by LECs was analyzed and quantified using FACs analysis. LECs co-cultured with OCUM12 cells showed significantly lower expression of MHC class II molecules. The data in the right-side panel are expressed as mean values of triplicates $\pm S D$. $* * p<0.01$.

effector immune responses but also of peripheral tolerance. Gastric cancer cells that have metastasized to the draining lymph nodes could have escaped immune surveillance, as reported previously $(23,24)$. However, very little is known regarding how immunological tolerance is regulated in the lymph nodes.

It has been reported that, in murine models, LECs can act as antigen-presenting cells (APCs) by expressing various peripheral tissue antigens to cross-present them to $\operatorname{CD} 8^{+}$ $\mathrm{T}$ cells $(3,7,8)$. Another report has shown that endothelial cells including LECs have the potential to interact with immune cells such as $\mathrm{T}$ cells and are potent stimulators of $\mathrm{CD}^{+} \mathrm{T}$ cell proliferation. However, most of these endothelial cells lack the capacity to activate naive $\mathrm{T}$ cells because of the absence of CD80 and CD86 expression (19).

Our study showed that INF-gamma stimulated LECs moderately express MHC class II molecules but do not express CD80 or CD86. Previous reports have shown that endothelial cells activate $\mathrm{CD}^{+} \mathrm{T}$ cells through $\mathrm{CD} 58 / \mathrm{CD} 2$ interaction $(17,20,21)$. Our results showed that LECs constitutively express CD58, and this finding indicated that LECs can deliver co-stimulatory signals to $\mathrm{CD}^{+} \mathrm{T}$ cells through the CD58/CD2 pathway. Most of the LECs used in previous reports were from "normal" tissues, such as murine and human skin. Similar to these LECs from "normal" tissues, the LECs from cancer draining lymph nodes of the present study can interact with $\mathrm{CD} 4^{+} \mathrm{T}$ cells; however, they do not have the ability to induce full activation of $\mathrm{T}$ cells because they do not express CD80 or CD86. More recently, LECs have been shown to be capable of cross-presenting antigens and of causing dysfunctional activation of $\mathrm{CD}^{+} \mathrm{T}$ cells under steady-state condition (7). Thus, LECs might be specialized for the induction of cancer immune tolerance by presenting a large number of tumor antigens to $\mathrm{T}$ cells in tumor draining lymph nodes. In the present study, $\mathrm{CD}^{+} \mathrm{T}$ cells failed to secrete cytokines after contact with LECs in an allogeneic proliferation assay, indicating that LECs from tumor draining lymph nodes were not able to activate CD4 ${ }^{+}$ $\mathrm{T}$ cells. Our results showed that these LECs expressed significantly higher levels of PD-L1 and IDO under an INFgamma stimulatory condition compared to non-stimulated controls. The PD-1/PD-L1 pathway has been reported to function as an inhibitory signal by regulating $\mathrm{T}$ cell functions and mediating peripheral tolerance (25-27). Cytokine production by $\mathrm{CD} 4^{+} \mathrm{T}$ cells is inhibited by the interaction of PD- 1 on the surface of the $\mathrm{CD} 4^{+} \mathrm{T}$ cells with PD-L1 on the surface of other cell types (28). An increase in the expression of IDO is one molecular mechanism that contributes to 


\section{PD-L1}

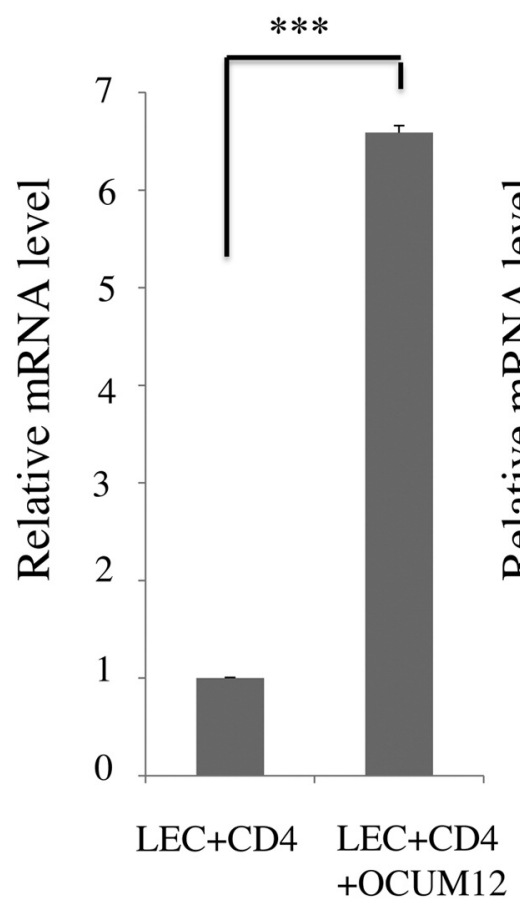

IDO

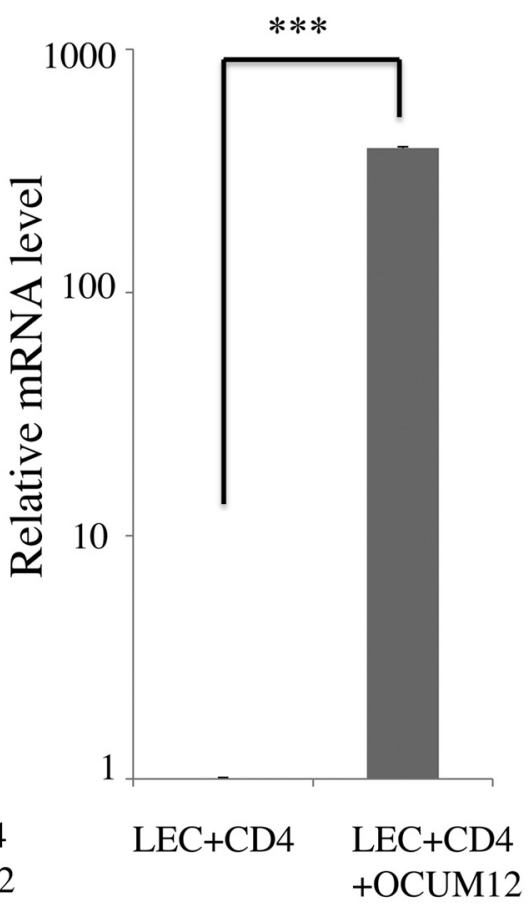

PD-1

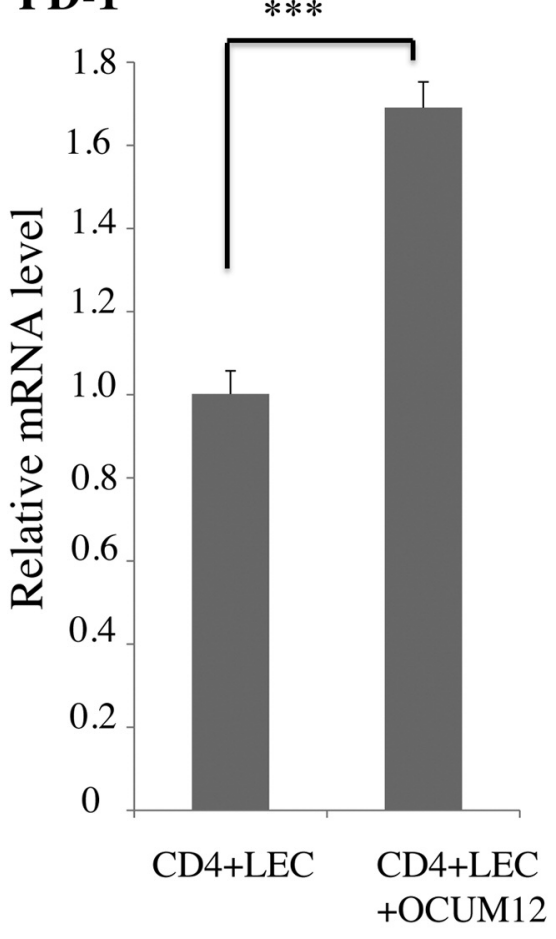

Figure 5. The effect of cancer cells on the mRNA expression of inhibitory molecules in LECs and CD4 ${ }^{+} T$ cells. LECs were co-cultured with CD4+ $T$ cells in the absence or presence of cells of the gastric cancer cell line OCUM12, and the mRNA expression of PD-L1, IDO, and PD-1 was analyzed using qRT-PCR. LECs co-cultured with CD4+ T cells in the presence of OCUM12 cells showed significantly higher mRNA expression of PD-L1 and IDO than LECs co-cultured with $C D 4^{+}$T cells. CD4 ${ }^{+}$T cells co-cultured with LECs in the presence of OCUM12 cells up-regulated the mRNA expression of PD-1 compared to CD4+ $T$ cells co-cultured with LECs. The mRNA expression levels are shown relative to those for the LEC plus $C D 4^{+} T$-cell co-culture. The data represent means of quintuplets $\pm S D$. ***p<0.001.

immunosuppression by suppressing $\mathrm{T}$ cell activation, inducing $\mathrm{T}$ cell anergy, and activating regulatory $\mathrm{T}$ cells (29, 30). Our results suggested that intranodal LECs may have the potential to respond to stimulation by up-regulating the expression of MHC class II molecules, as well as PD-L1 expression, resulting in a decreased ability of stromal cells to stimulate $\mathrm{T}$ cell proliferation. Thus, LECs in tumor draining lymph nodes may have a function similar to that of a "regulatory APC" due to their potential to regulate antitumor immune responses.

A connection between inflammation and cancer is now generally accepted. Cancer cells produce inflammatory mediators, thereby generating an inflammatory microenvironment around the tumor. Cytokines coordinate interactions between cancer cells and infiltrating immune cells, resulting in the invasion and metastasis of cancer cells. We showed down-regulation of MHC II and up-regulation of PD-L1 and IDO on the surface of LECs by co-culture of the LECs with cells of the OCUM12 human gastric cancer cell line. Importantly, PD-1 was up-regulated on $\mathrm{CD}^{+}{ }^{+} \mathrm{T}$ cells when the $\mathrm{CD}^{+}{ }^{+} \mathrm{T}$ cells were co-cultured with LECs in the added presence of OCUM12 cells, indicating that an immune regulatory effect of LECs is induced in draining lymph nodes. Our results suggested that LECs develop a tolerogenic microenvironment that facilitates immune evasion in draining lymph nodes by modulating the phenotype of the LECs so that they are disposed to immunosuppression. To the best of our knowledge, this is the first report in which the ability of LECs from tumor draining lymph nodes to suppress anti-tumor immune responses was examined.

However, there are some limitations to our study. One limitation is that we did not visualize the direct interaction of the LECs and $\mathrm{CD}^{+}{ }^{+} \mathrm{T}$ cells. Furthermore, it is not clear what molecules produced by cancer cells are involved in the modulation of LECs. It is possible that other soluble inhibitory molecules, such as nitric oxide and Transforming growth factor- $\beta$ (TGF- $\beta$ ), which cause abrogation of $\mathrm{CD}^{+}$ $\mathrm{T}$ cell function, may have played a role in the inhibition of $\mathrm{CD}^{+}{ }^{+} \mathrm{T}$ cell function observed in our co-culture system. Further experiments are necessary to understand the novel 
functions of lymph node LECs and their effects on local immune systems.

In conclusion, intranodal LECs may have an important role in inducing immune tolerance against cancer and may contribute to progression of gastric cancer through lymphatic systems. Although it has been considered that tumor-draining lymph nodes act as barriers against cancer, our findings suggested that tumor-draining lymph nodes induce immune tolerance in LECs. In addition, our study suggested that molecules associated with LECs might be potential biomarkers of novel immune therapy against gastric cancer.

\section{References}

1 Oliver $\mathrm{G}$ and Alitalo $\mathrm{K}$ : The lymphatic vasculature: recent progress and paradigms. Annu Rev Cell Dev Biol 21: 457-483, 2005.

2 Pepper MS and Skobe M: Lymphatic endothelium: morphological, molecular and functional properties. J Cell Biol 163: 209-213, 2003.

3 Cohen JN, Guidi CJ, Tewalt EF, Qiao H, Rouhani SJ, Ruddell A, Farr AG, Tung KS and Engelhard VH: Lymph node-resident lymphatic endothelial cells mediate peripheral tolerance via Aire-independent direct antigen presentation. J Exp Med 207: 681-688, 2010.

4 Fletcher AL, Lukacs-Kornek V, Reynoso ED, Pinner SE, Bellemare-Pelletier A, Curry MS, Collier AR, Boyd RL and Turley SJ: Lymph node fibroblastic reticular cells directly present peripheral tissue antigen under steady-state and inflammatory conditions. J Exp Med 207: 689-697, 2010.

5 Lee JW, Epardaud M, Sun J, Becker JE, Cheng AC, Yonekura AR, Heath JK and Turley SJ: Peripheral antigen display by lymph node stroma promotes $\mathrm{T}$ cell tolerance to intestinal self. Nat Immunol 8: 181-190, 2007.

6 Podgrabinska S, Kamalu O, Mayer L, Shimaoka M, Snoeck H, Randolph GJ and Skobe M: Inflamed lymphatic endothelium suppresses dendritic cell maturation and function via Mac-1/ICAM1-dependent mechanism. J Immunol 183: 1767-1779, 2009.

7 Hirosue S, Vokali E, Raghavan VR, Rincon-Restrepo M, Lund AW, Corthesy-Henrioud P, Capotosti F, Halin Winter C, Hugues $\mathrm{S}$ and Swartz MA: Steady-state antigen scavenging, crosspresentation, and $\mathrm{CD} 8+\mathrm{T}$ cell priming: a new role for lymphatic endothelial cells. J Immunol 192: 5002-5011, 2014.

8 Lund AW, Duraes FV, Hirosue S, Raghavan VR, Nembrini C, Thomas SN, Issa A, Hugues S and Swartz MA: VEGF-C promotes immune tolerance in B16 melanomas and crosspresentation of tumor antigen by lymph node lymphatics. Cell Rep 1: 191-199, 2012.

9 Dunn GP, Bruce AT, Ikeda H, Old LJ and Schreiber RD: Cancer immunoediting: from immunosurveillance to tumor escape. Nat Immunol 3: 991-998, 2002.

$10 \mathrm{Kim} \mathrm{R}$, Emi $\mathrm{M}$ and Tanabe $\mathrm{K}$ : Cancer immunoediting from immune surveillance to immune escape. Immunology 121: 1-14, 2007.

11 Okita Y, Tanaka H, Ohira M, Muguruma K, Kubo N, Watanabe M, Fukushima W and Hirakawa K: Role of tumor-infiltrating $\mathrm{CD}_{11} \mathrm{~b}^{+}$antigen-presenting cells in the progression of gastric cancer. J Surg Res 186: 192-200, 2014.
12 Go Y, Tanaka H, Tokumoto M, Sakurai K, Toyokawa T, Kubo N, Muguruma K, Maeda K, Ohira M and Hirakawa K: TumorAssociated Macrophages Extend Along Lymphatic Flow in the Pre-metastatic Lymph Nodes of Human Gastric Cancer. Ann Surg Oncol 23(Suppl 2): S230-235, 2016.

13 Watanabe M, Tanaka H, Ohira M, Yoshii M, Sakurai K, Toyokawa T, Kubo N, Yamamoto A, Muguruma K, Yamashita $\mathrm{Y}$, Maeda $\mathrm{K}$, Sawada $\mathrm{T}$ and Hirakawa $\mathrm{K}$ : Intranodal lymphangiogenesis precedes development of lymph node metastasis and accelerates progression of gastric cancer. J Gastrointest Surg 18: 481-490, 2014.

14 Tokumoto MW, Tanaka H, Tauchi Y, Kasashima H, Kurata K, Yashiro M, Sakurai K, Toyokawa T, Kubo N, Amano R, Kimura K, Muguruma K, Maeda K, Ohira M and Hirakawa K: Identification of tumour-reactive lymphatic endothelial cells capable of inducing progression of gastric cancer. Br J Cancer 113: 1046-1054, 2015.

15 Kato Y, Yashiro M, Noda S, Tendo M, Kashiwagi S, Doi Y, Nishii T, Matsuoka J, Fuyuhiro Y, Shinto O, Sawada T, Ohira M and Hirakawa K: Establishment and characterization of a new hypoxiaresistant cancer cell line, OCUM-12/Hypo, derived from a scirrhous gastric carcinoma. Br J Cancer 102: 898-907, 2010.

16 Cunningham AC, Zhang JG, Moy JV, Ali S and Kirby JA: A comparison of the antigen-presenting capabilities of class II MHC-expressing human lung epithelial and endothelial cells. Immunology 91: 458-463, 1997.

17 Hansen $\mathrm{AB}$, Bouchelouche $\mathrm{K}$ and Olesen JD: Human lung microvascular endothelial cells activate allogeneic $\mathrm{T}$ cells through an LFA-3-dependent, but CD86-independent mechanism. APMIS 109: 849-856, 2001.

18 Marelli-Berg FM, Hargreaves RE, Carmichael P, Dorling A, Lombardi $G$ and Lechler RI: Major histocompatibility complex class II-expressing endothelial cells induce allospecific nonresponsiveness in naive T cells. J Exp Med 183: 1603-1612, 1996.

19 Norder M, Gutierrez MG, Zicari S, Cervi E, Caruso A and Guzman CA: Lymph node-derived lymphatic endothelial cells express functional costimulatory molecules and impair dendritic cell-induced allogenic T-cell proliferation. FASEB J 26: 28352846, 2012.

20 Savage CO, Hughes CC, Pepinsky RB, Wallner BP, Freedman AS and Pober JS: Endothelial cell lymphocyte functionassociated antigen- 3 and an unidentified ligand act in concert to provide costimulation to human peripheral blood $\mathrm{CD} 4{ }^{+} \mathrm{T}$ cells. Cell Immunol 137: 150-163, 1991.

21 Hughes CC, Savage CO and Pober JS: Endothelial cells augment $\mathrm{T}$ cell interleukin 2 production by a contact-dependent mechanism involving CD2/LFA-3 interaction. J Exp Med 171: 1453-1467, 1990.

22 Keir ME, Butte MJ, Freeman GJ and Sharpe AH: PD-1 and its ligands in tolerance and immunity. Annu Rev Immunol 26: 677704, 2008.

23 Yoshii M, Tanaka H, Ohira M, Muguruma K, Sakurai K, Kubo N, Yashiro M, Sawada T and Hirakawa K: Association of MHC class I expression and lymph node metastasis of gastric carcinoma. Hepatogastroenterology 60: 611-615, 2013.

24 Maehara Y, Tomisaki S, Oda S, Kakeji Y, Tsujitani S, Ichiyoshi Y, Akazawa $\mathrm{K}$ and Sugimachi K: Lymph node metastasis and relation to tumor growth potential and local immune response in advanced gastric cancer. Int J Cancer 74: 224-228, 1997. 
25 Riella LV, Paterson AM, Sharpe AH and Chandraker A: Role of the PD-1 pathway in the immune response. Am J Transplant 12: 2575-2587, 2012.

26 Tewalt EF, Cohen JN, Rouhani SJ, Guidi CJ, Qiao H, Fahl SP, Conaway MR, Bender TP, Tung KS, Vella AT, Adler AJ, Chen $\mathrm{L}$ and Engelhard VH: Lymphatic endothelial cells induce tolerance via PD-L1 and lack of costimulation leading to highlevel PD-1 expression on CD8 T cells. Blood 120: 4772-4782, 2012.

27 Pardoll DM: The blockade of immune checkpoints in cancer immunotherapy. Nat Rev Cancer 12: 252-264, 2012.

28 Keir ME, Liang SC, Guleria I, Latchman YE, Qipo A, Albacker LA, Koulmanda M, Freeman GJ, Sayegh MH and Sharpe AH: Tissue expression of PD-L1 mediates peripheral T cell tolerance. J Exp Med 203: 883-895, 2006.
29 Mellor AL and Munn DH: IDO expression by dendritic cells: tolerance and tryptophan catabolism. Nat Rev Immunol 4: 762 774, 2004.

30 Munn DH and Mellor AL: Indoleamine 2,3-dioxygenase and tumor-induced tolerance. J Clin Invest 117: 1147-1154, 2007.

Received April 13, 2017

Revised April 26, 2017

Accepted April 27, 2017 